\title{
Enhancement of Rice Yield Through Introgression of Drought Tolerance QTL in Swarna Sub 1 (Oryza sativa L.) Using MAS Based Approaches
}

\author{
Sonam Kale Sureshrao*, Chavan Narendra Rameshsing, Kadu Tanvi Pradeeprao, Archana Prasad and S. B. Verulkar \\ Dept. of Plant Molecular Biology and Biotechnology, IGKV, Krishak nagar, Raipur, C.G. (492 012), India.
}

\section{Article History}

Manuscript No. AR1577

Received in $24^{\text {th }}$ April, 2016

Received in revised form $15^{\text {th }}$ July, 2016

Accepted in final form $29^{\text {th }}$ July, 2016

\section{Correspondence to}

*E-mail: sonamkale09@gmail.com

\section{Keywords}

Rice, drought, terminal stage drought, marker assisted selection

\begin{abstract}
Rice is a highly drought sensitive crop, and most semi-dwarf high yielding varieties suffer severe yield losses from reproductive stage drought stress in Chhattisgarh. In Chhattisgarh, rice variety swarna sub1, covers major area is the most popular high yielding variety in central India, however is susceptible to water stress (Drought), which is quietly frequently occurs in recent past leading to significant yield losses. We studied 10 yield contributing physiological traits under irrigated, and terminal stage drought (TSD) conditions in $\mathrm{F}_{2}$ and $\mathrm{F}_{3}$ progenies derived from the crossed of swarna sub1 (Drought susceptible) and IR 84984-83-15-159B (Drought tolerant). Genotypic study was done using peak primers/markers for targeted region on chromosome 12 to know the presence of $q D T Y 12.1$ in swarna sub1 lines which were resistant to drought stress. The molecular marker analysis revealed that polymorphic markers RM511, RM1261, RM28130, RM7195 and RM28099 shows significant association with different yield contributing physiological traits. Out of these markers the marker RM511, RM1261 and RM28130 were significantly associated with grain yield under TSD condition. Statistical analysis for the PCV and GCV revealed that in both the conditions i.e. irrigated (control) and Terminal stage drought (TSD), the estimates of phenotypic co-efficient of variation (PCV) were higher than the corresponding estimates of genotypic co-efficient of variation $(\mathrm{GCV})$ for all the traits/characters. Association of phenotypic and genotypic data revealed that line number 4, 21, 28, $32,35,36$ and 37 were co-segregated with polymorphic markers and these lines were similar to the swarna sub1 morphologically with QTL 12.1 having drought tolerance.
\end{abstract}

\section{Introduction}

Rice (Oryza sativa L.) is a "Global Grain" cultivated widely across the world feeding millions of mankind. Grain yield is major important component for breeder and farmers. Grain yield is a complex character and is controlled by many factors. Drought is by far the most important environmental stress in agriculture and many efforts have been made to improve crop productivity under water-limiting conditions. At least $30.9 \%$ of the total rice area around the world is rainfed and is subjected to variable intensities of drought and flood. The suitability of grain yield (GY) under drought as a selection criterion has been reported in the past few years. Most of the quantitative trait loci (QTLs) for GY under drought in rice reported so far has been in the background of low-yielding susceptible varieties. Such QTLs have not shown a similar effect in multiple high- yielding drought-susceptible varieties, thus limiting their use in markerassisted selection (Vikram et al., 2011). Drought is one of the major abiotic stresses that lead to a decline in rice production in the rainfed areas. In Asia alone, a total of 23 mha of rice area is affected by drought of variable intensities. The use of grain yield as a selection criterion, through proper population development and precise phenotyping techniques, has allowed the development of several high-yielding rice cultivars that have been released in major rainfed rice-growing areas. This strategy has also allowed the identification of several major quantitative trait loci (QTLs) that show large effects under drought across environments and genetic backgrounds.

The slow progress in developing rice varieties for drought-prone areas is mainly due to the complex nature of drought-tolerance mechanisms; large genotype $\times$ environment, QTL $\times$ environment and QTL $\times$ recipient genetic background interactions; and the absence of QTLs with a large and consistent effect against high-yielding but drought-susceptible varieties. Not only the interactions but also the complex nature of drought, which affects the rice plant at all stages of crop growth, and its relation with a number of physiological mechanisms and biochemical 
pathways further complicate the problem. Therefore, a strategy of screening in different environments, particularly in the target population of environments (TPE), is advocated for developing varieties with broader adaptation (Fukai et al.,1995). Most of the high-yielding varieties IR36, IR64, MTU1010, Swarna, and Samba Mahsuri-grown in rainfed areas are varieties bred for the irrigated ecosystem and they were never selected for drought tolerance. In drought years, these varieties have high yield losses, leading to a significant decline in rice production (Kumar et al., 2008). In the absence of highyielding, good-quality drought-tolerant varieties, farmers in the rainfed ecosystem continue to grow these drought-susceptible varieties. Knowledge of interrelationship between yield and its components is obvious for efficient selection of desirable sergeants in plant breeding. Mishra et al. (2013) reported QTL, qDTY 12.1 (between RM 511 and RM 28166) for grain yield under drought condition in rice. This QTL showed a consistent effect across environments for high grain yield under lowland reproductive stage drought stress.

The basis of a marker-assisted backcrossing (MAB) strategy is to transfer a specific allele at the target locus from a donor line to a recipient line while selecting against donor introgressions across the rest of the genome. The main advantages of MAB are: (1) efficient foreground selection for the target locus, (2) efficient background selection for the recurrent parent genome, (3) minimization of linkage drags surrounding the locus being introgressed, and (4) rapid breeding of new genotypes with favorable traits and hence it is an effective way to introgressed a region of interest into other cultivars. The rigorous work at IGKV and other centers has resulted in the identification of agronomically relevant quantitative trait loci (QTLs) that can be deployed to improve rice yield under drought. The objectives of our investigation were (1) to develop a drought-tolerant version of the widely grown cultivar swarna sub1 within a 2-3 years' timeframe through a targeted MAS approach for the QTL $q D T Y$ 12.1. For developing the new drought tolerance rice cultivar swarna sub1, an attempt has been made to introgressed the drought tolerance QTL 12.1 from donor IR 84984-83-15-159B and was extensively screened under well-defined managed water stress conditions under irrigated, and terminal stage drought (TSD) conditions and in summers for vegetative stage screening.

\section{Materials and Methods}

The study was conducted in plant molecular laboratory at dept. of plant molecular biology and biotechnology as well as field study for phenotyping of physiological traits was done during wet season of 2014 and summer 2015 at research come experimental field of Directorate of Research Station is situated at latitude $14^{\circ} 13^{\prime} \mathrm{N}$ and longitude $121^{\circ} 15^{\prime} \mathrm{E}$., Indira Gandhi Agricultural University, Raipur, Chhattisgarh, India. For field studies the plant population, obtained from cross between two parents were planted out in a field during wet season of kharif-2014 and summer-2015 at the experimental farm.

\subsection{Population development}

In this present investigation, IR 84984-83-15-159B one of the drought-tolerant breeding lines, short duration (90-95 days) was used as the donor for QTL12.1. The second parent swarna sub1 is a semi-dwarf high-yielding medium-duration (112-118 days) but susceptible to drought stress was used and the crossed was made between these two parents to develop the plant population. Single seeds from each $\mathrm{F}_{2}$ plant were selected and $\mathrm{F}_{3}$ seeds obtained were grown under control (Irrigated) as well as TSD conditions and harvested individually. 320 $\mathrm{F}_{3}$ plants from the population were harvested and grown in KH- 2014 wet season.

\subsection{Phenotyping and selection of lines}

The $320 \mathrm{~F}_{3}$ plant populations were grown under irrigated and TSD condition and the data were recorded for all 10 physiological phenotypic traits. The observations for physiological traits contributing for yield traits were recorded at plant specific stage during their maximum tillering stage, vegetative stage, maturation stage were recorded according to SES (standard evaluation system), IRRI 2002. The fixed five plants were selected from each line and the observations were recorded all the physiological traits. The physiological traits such as Plant height, Panicle length, Flag leaf length, Flag leaf width, Second leaf length, second leaf width, Number of panicle plant ${ }^{-1}$, Bundle weight, grain yield and harvest index has been recorded in order to check the effect of QTL 12.1 under both conditions.

For precise phenotyping of these lines each line was transplanted in one meter square area and the plant to plant distance was $15 \times 15 \mathrm{~cm}^{2}$. After recording data for all above mentioned traits on that basis of these, the subset of these population i.e. 55 lines were selected and again screened in summer 2015 for all yield traits.

\subsection{Molecular marker analysis}

\subsubsection{DNA extraction and PCR amplification}

The genotypic data was generated based on 12 gene specific SSR markers (Table 1). The DNA was extracted from young leaf of selected 55 lines with the help of MiniPrep method (Doyle and Doyle, 1987). The DNA samples were quantified using Nanodrop Spectrophotometer (ND 100) and the absorbance ratio (A260/A280) was recorded for each sample to find out the purity of DNA. Polymerase chain reaction (PCR) amplification was performed in a total volume of 20 $\mu \mathrm{l}$ and the reaction mixture contained $10 \mathrm{X}$ Assay buffer, 1 $\mathrm{mM}$ dNTP mix, $5 \mathrm{pM}$ forward and reverse primers, $40 \eta \mathrm{g}$ of template DNA and 1 unit Taq polymerase in Applied Biosystems thermal cycler. The PCR reaction was carried out at, initial denaturation step of $94{ }^{\circ} \mathrm{C}$ for $5 \mathrm{~min}, 34$ cycles 
comprising $30 \mathrm{sec}$ each of $94^{\circ} \mathrm{C}, 55^{\circ} \mathrm{C}$ and $1 \mathrm{~min}$ at $72^{\circ} \mathrm{C}$. The final elongation step was extended to $7 \mathrm{~min}$ at $72^{\circ} \mathrm{C}$ followed by storage at $4{ }^{\circ} \mathrm{C}$. A total $12 \mathrm{SSR}$ markers targeted to QTL 12.1 were used to identify which lines of plant population having region of interest. First the parental polymorphism was checked using 12 markers, out of these only five markers were polymorphic. Later that the whole plant population were genotyped using five polymorphic markers RM511, RM1261, RM28130, RM7195 and RM28099.

\subsubsection{Resolving PCR product on PAGE}

After the PCR reaction was completed, $5 \mu \mathrm{l}$ of $6 \mathrm{X}$ loading dye was added to PCR amplicons and $5 \mu$ (PCR product with dye) was loaded on 5\% PAGE in a mini vertical electrophoresis system (CBS scientific, model MGV-20233). The gels were stained in $10 \mathrm{mg} \mathrm{ml}^{-1}$ ethidium bromide and were visualized using with a UV trans illuminator BioRad XLR+. The banding pattern was scored in A (p1 type band), B (p2 type band) and $\mathrm{H}$ (for heterozygous) obtained after gel documentation.

\subsection{Statistical analysis}

The genotypic data of the whole mapping population was developed however for the purpose of QTL identification, genotypes were selected from extreme classes and thus selective genotyping method was used to detect the association of QTLs with traits. Bernier et al. (2008) also report to used selective genotyping for QTL detection. Test for QTL association with traits was performed by single marker analysis approach. The single marker analysis, $t$-test was followed to find out the significant association between traits and the markers.

Association between agronomic trait and markers were calculated using ANOVA: single marker analysis (SMA). The significant marker trait associations were indicated by a $p$-value $(<0.05)$ with corresponding $\mathrm{R}^{2}$. Phenotypic and genotypic coefficient of variations was estimated according to Burton and De vane (1953) Genetic advance was calculated according to formula given by Johnson et al. (1955) and heritability was estimated according to Allard (1962).

\section{Results and Discussion}

\subsection{Trait analysis}

Breeding for drought tolerance is a high-priority area of rice research for sustainable production as the severity and

\begin{tabular}{|c|c|c|c|c|c|c|c|}
\hline \multirow{2}{*}{$\begin{array}{l}\text { Sl. } \\
\text { No. }\end{array}$} & \multirow[t]{2}{*}{ Markers } & \multirow[t]{2}{*}{ Motif } & \multirow[t]{2}{*}{ Forward primer } & \multirow[t]{2}{*}{ Reverse primer } & \multirow{2}{*}{$\begin{array}{l}\text { Prod- } \\
\text { uct size }\end{array}$} & \multicolumn{2}{|c|}{ Genomic position } \\
\hline & & & & & & SSR start & SSR end \\
\hline 1. & RM511 & $\mathrm{ACG}$ & $\begin{array}{l}\text { AACGAAAGC- } \\
\text { GAAGCTGTCTCC }\end{array}$ & $\begin{array}{l}\text { ATTTGTTCCCTTCCTTC- } \\
\text { GATCC }\end{array}$ & 143 & 17442508 & 17442528 \\
\hline 2. & RM1261 & $\mathrm{AG}$ & $\begin{array}{l}\text { ATGGTAGAGACA- } \\
\text { CAAGTCCATGC }\end{array}$ & $\begin{array}{l}\text { GACAAATTGGTGTAG- } \\
\text { GTGAAGG }\end{array}$ & 218 & 17578154 & 17578185 \\
\hline 3. & RM28099 & $\mathrm{CCG}$ & $\begin{array}{l}\text { TGTGCGGATGC- } \\
\text { GGGTAAGTCC }\end{array}$ & $\begin{array}{l}\text { CCACCTGTCAACCAC- } \\
\text { CGAAACC }\end{array}$ & 121 & 15896826 & 15896846 \\
\hline 4. & RM3739 & $\mathrm{AG}$ & $\begin{array}{l}\text { CTAAGATCCAAC- } \\
\text { GGGTTCTGTGC }\end{array}$ & $\begin{array}{l}\text { TTGTGTGCACTTC- } \\
\text { GTCTTCAACC }\end{array}$ & 377 & 25036232 & 25036263 \\
\hline 5. & RM28076 & $\mathrm{AG}$ & $\begin{array}{l}\text { GGGACTTGGGAC- } \\
\text { CAGTTTATGG }\end{array}$ & $\begin{array}{l}\text { TCAGGTCTGTTGGATTC- } \\
\text { CATGC }\end{array}$ & 290 & 15182075 & 15182100 \\
\hline 6. & RM28199 & AGAT & $\begin{array}{l}\text { CGGCTTAGGGAGC- } \\
\text { GTCTGTAGG }\end{array}$ & $\begin{array}{l}\text { GCATGCTAGTATGGC- } \\
\text { CACCATATTCC }\end{array}$ & 180 & 18225086 & 18225105 \\
\hline 7. & RM28130 & AGG & $\begin{array}{l}\text { CAGCAGACGTTCC- } \\
\text { GGTTCTACTCG }\end{array}$ & $\begin{array}{l}\text { AGGACGGTGGTGGT- } \\
\text { GATCTGG }\end{array}$ & 176 & 16748364 & 16748384 \\
\hline 8. & RM7195 & AGAT & $\begin{array}{l}\text { GCCACTGGAAA- } \\
\text { CAATTGAAACG }\end{array}$ & $\begin{array}{l}\text { CGCTTTGTCCTTGTGTA- } \\
\text { ACTACCG }\end{array}$ & 322 & 9895647 & 9895674 \\
\hline 9. & RM28048 & $\mathrm{CCG}$ & $\begin{array}{l}\text { TTCAGCCGATC- } \\
\text { CATTCAATTCC }\end{array}$ & $\begin{array}{l}\text { GCTATTGGCCGGAAAG- } \\
\text { TAGTTAGC }\end{array}$ & 94 & 14153465 & 14153488 \\
\hline 10. & RM28186 & AT & $\begin{array}{l}\text { AGGCAGATAAGT- } \\
\text { GAGGCATACGG }\end{array}$ & $\begin{array}{l}\text { ACTGGCTGACCCATC- } \\
\text { TACCAACC }\end{array}$ & 398 & 17936480 & 17936499 \\
\hline 11. & RM28089 & ATC & $\begin{array}{l}\text { GGGAGGACACCT- } \\
\text { GTGTAAGTAGG }\end{array}$ & $\begin{array}{l}\text { GGTTCAAATGAGA- } \\
\text { CCCAATTCC }\end{array}$ & 261 & 15458800 & 15458835 \\
\hline 12. & RM28086 & $\mathrm{AC}$ & $\begin{array}{l}\text { CCCGCTGCAG- } \\
\text { CAGTTTATTGAGG }\end{array}$ & $\begin{array}{l}\text { GATCTGGTACCTG- } \\
\text { CATGGGTTGC }\end{array}$ & 388 & 15384525 & 15384550 \\
\hline
\end{tabular}


frequency of drought occurrences are expected to increase because of the ongoing climatic change process (Wassmann $\mathrm{R}$ et al., 2009; Bate Bc et al., 2008). There is an urgent need to breed drought-tolerant rice varieties with high yield potential. The phenotypic data analysis of experiment's revealed highly significant differences among the different physiological traits viz., plant height, number of tillers, Panicle length, number of panicle plant ${ }^{-1}$, flag leaf length, flag leaf width, second leaf length, Second leaf width, biological yield, grain yield and harvest index.

The statistical analysis of both the data shows varying degree of differences. In both the conditions i.e. irrigated (control) and terminal stage drought (TSD), the estimates of phenotypic co-efficient of variation (PCV) were higher than the corresponding estimates of genotypic co-efficient of variation (GCV) for all the traits/characters (Table 2 and 3). Study of GCV help to measure the range of genetic variation existed in the specific environmental site. Comparative study of coefficient of variation on various characters revealed relatively high contribution of genotypic variation in determining the total phenotypic variation for most of the characters. In control as well as in TSD condition the traits like Harvest Index (HI) and grain yield (GY) exhibited high value of GCV while the lowest GCV was observed for Panicle length (PL), Flag leaf width (FLW), second leaf length (SLL) and Second leaf width (SLW). But the GCV value for trait Flag leaf length (FLL) is more in TSD as compared to control but vice versa in case of bundle weight $(\mathrm{BWt})$. Similarly under control condition the high estimate of PCV was observed for the traits i.e. Harvest Index (HI), grain yield (GY), biological yield (BI), plant height (PHT), second leaf length (SLL), second leaf width (SLW), No. of panicle plant ${ }^{-1}$ (NPPP), flag leaf length and fag leaf width (FLW) except panicle length (PL) for which GCV as well as PCV is very low. PCV for flag leaf width (FLW) and Second leaf width (SLW) is less under TSD condition.

Higher PCV value as compared to GCV value for all the character suggest that apparent variation is not entirely due to genotypes but also due to influence of environment and selection for such traits may be sometime misleading. In the present investigation the difference between PCV and GCV were narrow for most of the characters. Indicating the effect of the environment on these traits is low. High difference between

Table 2: Overall mean, Range, along with variability parameters for different characters under control (Irrigated) condition

\begin{tabular}{lccccccc}
\hline Sl. No. & Traits & Overall means & range & GCV & PCV & Heritability $(\%)$ & GA\% means \\
\hline 1. & PHT & 131.549 & $94-154$ & 8.398 & 10.745 & 61.09 & 13.523 \\
2. & PL & 23.730 & $18-27$ & 6.938 & 11.979 & 33.53 & 8.277 \\
3. & FLL & 36.006 & $28-50$ & 10.419 & 12.728 & 67.00 & 17.568 \\
4. & FLW & 1.541 & $1.2-1.8$ & 6.069 & 9.810 & 38.27 & 7.735 \\
5. & SLL & 55.604 & $39-70$ & 9.927 & 11.545 & 73.93 & 17.584 \\
6. & SLW & 1.188 & $0.93-14$ & 8.092 & 9.881 & 67.07 & 13.520 \\
7. & NPPP & 7.518 & $5-12$ & 17.488 & 21.563 & 65.77 & 29.216 \\
8. & BWt & 1485.664 & $1080-1900$ & 9.397 & 13.376 & 49.35 & 13.599 \\
9. & GY & 183.300 & $69-454$ & 47.303 & 50.294 & 88.45 & 91.648 \\
10. & HI & 13.509 & $6-28$ & 40.533 & 45.323 & 79.97 & 74.725 \\
\hline
\end{tabular}

Table 3: Overall mean, range, along with variability parameters for different characters under stress (TSD) condition

\begin{tabular}{lccccccc}
\hline Sl. No. & Traits & Overall means & range & GCV & PCV & Heritability $(\%)$ & GA\% means \\
\hline 1. & PHT & 156.300 & $99-175$ & 10.018 & 10.798 & 86.068 & 19.145 \\
2. & PL & 24.502 & $19-28$ & 5.741 & 8.791 & 42.647 & 7.723 \\
3. & FLL & 35.211 & $28-46$ & 7.288 & 12.909 & 31.871 & 8.475 \\
4. & FLW & 1.154 & $0.8-1.5$ & 8.876 & 14.106 & 39.592 & 11.505 \\
5. & SLL & 49.013 & $37-61$ & 9.387 & 11.656 & 74.851 & 15.572 \\
6. & SLW & 0.872 & $0.7-1.7$ & 6.506 & 23.485 & 66.76 & 3.713 \\
7. & NPPP & 6.235 & $5-10$ & 9.105 & 19.829 & 21.084 & 8.612 \\
8. & BWt & 1,577 & $1100-2200$ & 13.395 & 14.745 & 82.518 & 25.065 \\
9. & GY & 26.894 & $271-710$ & 18.673 & 21.221 & 77.427 & 33.848 \\
10. & HI & 420.114 & $18-43$ & 21.732 & 22.289 & 95.065 & 43.649 \\
\hline
\end{tabular}


GCV and PCV was found in case of No. of panicle plant ${ }^{-1}$ (NPPP), Flag leaf length (FLL), Second leaf width (SLW) and Root pulling strength (RPS). Wide range of phenotypic and genotypic co-efficients of variation (PCV and GCV) was observed among the quantitative traits by Kumar et al. (2003); Gupta et al. (2004). Whereas Hozayn et al. (2013) found that the PCV was approximately equal to GCV for most of the traits.

High estimates of heritability (broad sense) value $(>70 \%)$ were obtained for Grain yield (GY), Second leaf length (SLL) and Harvest index (HI) in both the conditions whereas under control condition the plant height (PHT) and Bundle weight (BWt) also show $>70 \%$ variability. But under TSD, the traits such as Plant height (PHT), Flag leaf length (FLL), Second leaf width (SLW), No. of panicle plant ${ }^{-1}$ (NPPP) and Bundle weight (BWt) showed moderate level (40-70\%) of heritability .

The trait Plant height (86.06) in control condition show more heritability percent as compared to TSD (61.09). But besides these physiological traits some traits like panicle length (PL), Fag leaf width (FLW) under control condition and the traits, Flag leaf length (FLL), Fag leaf width (FLW) and No. of panicle plant ${ }^{-1}$ (NPP) under TSD exhibit very low $(=/<40 \%)$ estimate of heritability. This indicated that most likely cause of heritability for these characters is due to additive gene action and as such selection for these characters is likely to accumulate more additive genes leading to scope for potential improvement in their performance. According to Panse (1957), the magnitude of heritable value is the most important aspect of genetic constitution of breeding material, which has close bearing on the response to selection. Further, heritability estimates along with genetic advance are normally more useful in predicting the gain under selection than heritability estimates alone (Singh and Narayanan, 1993).

The genetic advance (GA) estimates was vary from 7.73 to 91.64 and 3.71 to 43.64 under TSD and control set of condition resp. The highest estimate of genetic advance was observed in drought condition as compared to control. Out of both the conditions the Grain yields under TSD give the $91.64 \%$ GA which was highest among all those traits and lowest genetic advance was found in case of for Second leaf width (SLW) $3.71 \%$ under control condition. Heritability estimates and genetic advance was high for Grain yield (GY) and Harvest index (HI) suggests that the high heritability most likely due to additive gene effect and selection may be effective.

In the present investigation all physiological traits in both the condition exhibited high heritability but low genetic advance which is indicative of non-additive gene action (dominance and epistasis) and presence of $\mathrm{G} \times \mathrm{E}$ interaction. It exhibited due to favorable influence of environment rather than genotype, and selection for such traits may not be rewarding. The traits which showed low heritability and low genetic advance, it indicates that the character is highly influenced by environmental effects and selection would be ineffective.

\subsection{Marker trait association analysis}

Developing rice varieties with high GY under drought is necessary for obtaining sustainable rice yields in drought prone areas. Popular farmer-accepted varieties could be improved for high grain yield (GY) under reproductive stage (RS) by following fast-track MAB approaches. In the current study the association between trait and markers were identified on the basis of genotypic and phenotypic data. DNA markers that show specific molecular weight bands in the selected lines across the total population were genetically linked to the loci determining the quantitative trait.

Marker trait association was identified in both the conditions such as irrigated (control) and TSD. The result revealed that in both the conditions each of total 16 marker trait associations were identified (Table 4) for different yield contributing traits on chromosome \#12. Recent studies identified that the marker RM511 was peak marker for QTL 12.1 in different population.

Table 4: Association between SSR markers and agronomic traits with $p<0.05$ under controlled condition (Irrigated) and terminal stage drought (TSD)

\begin{tabular}{llccccc}
\hline Sl. & Marker & Trait & \multicolumn{2}{c}{$p$ value } & \multicolumn{2}{c}{$\mathrm{R}^{2 \%}$} \\
\cline { 4 - 7 } No. & & & Control & Stress & Control & Stress \\
\hline 1. & RM511 & FLL & 0.04 & 0.05 & 11.04 & 10.21 \\
2. & RM511 & 2FLL & 0.01 & - & 14.76 & - \\
3. & RM511 & HI & 0.03 & 0.05 & 12.08 & 10.00 \\
4. & RM511 & PHT & 0.05 & 0.02 & 9.06 & 13.26 \\
5. & RM511 & GY & - & 0.04 & - & 11.00 \\
6. & RM1261 & GY & - & 0.05 & - & 9.97 \\
7. & RM1261 & PHT & 0.02 & 0.05 & 12.68 & 10.55 \\
8. & RM1261 & HI & - & 0.04 & - & 10.88 \\
9. & RM28130 & PHT & 0.02 & - & 13.55 & - \\
10. & RM28130 & FLL & 0.05 & 0.04 & 9.32 & 11.59 \\
11. & RM28130 & GY & - & 0.006 & - & 17.58 \\
12. & RM28130 & HI & - & 0.005 & - & 17.99 \\
13. & RM28130 & FLW & 0.05 & - & 9.55 & - \\
14. & RM28130 & 2LL & 0.006 & 0.05 & 17.68 & 9.59 \\
15. & RM7195 & PHT & 0.05 & 0.02 & 9.7 & 13.34 \\
16. & RM7195 & FLW & 0.05 & - & 10.55 & - \\
17. & RM7196 & 2LL & 0.05 & 0.01 & 10.18 & 14.5 \\
18. & RM7195 & FLL & - & 0.001 & - & 22.55 \\
19. & RM7195 & HI & - & 0.05 & - & 10.2 \\
20. & RM28099 & PHT & 0.001 & 0.01 & 21.86 & 12.26 \\
21. & RM28099 & 2LL & 0.005 & - & 9.96 & - \\
22. & RM28099 & BY & 0.05 & - & 10.11 & - \\
23. & RM28099 & HI & 0.05 & - & 10.33 & - \\
\hline & & & & & &
\end{tabular}


In this study under controlled condition no one marker was identified for grain yield while under TSD the markers RM511, RM1261 and RM28130 were linked to grain yield. This revealed that the presence of QTL12.1 which increases the grain yield under drought with the phenotypic variance $\left(\mathrm{R}^{2}\right)$ was $11 \%, 9.97 \%$ and $17.58 \%$ respectively. RM511 was also affect the traits like plant height (PHT) in water stress (TSD) however flag leaf length (FLL), Harvest index (HI) in both the conditions. Recently, qDTY 1.1 has been reported to show a large effect against three recipient backgrounds (Vikram et al., 2011). Earlier, a CT9993-5-10-1-M/IR62266-42-6-2 population was screened at multi-locations and different QTLs were reported to show tolerance by different authors. In a study conducted by Babu et al. (2003), QTL gys 1.1 affecting grain yield under stress was reported between EM18_10 and L1087 at 113.2-122.2 cM (www.gramene.org) on chromosome 1.

For a QTL to be widely adopted in a MAS/MAB program, it is necessary that it show a large and consistent effect in different environments, against the genetic background of different recipient drought-susceptible varieties and across ecosystems, upland and lowland. However, in the literature, no such QTL has been reported so far. $q D T Y 12.1$ has been reported previously in a population derived from the cross of upland cultivars Vandana and Way Rarem, in which it explained a genetic variance of $51 \%$ for GY under upland reproductive stage (Bernier et al., 2007).

Another marker RM1261 was associated with Plant height (PHT), grain yield (GY) and harvest index (HI) having the phenotypic variance (R2) $10.55 \%, 9.97 \%$ and $10.88 \%$ under TSD and under control condition this marker linked to plant height (PHT) only and $\mathrm{R}^{2}$ was $12.68 \%$. Another polymorphic marker nearer to RM 511 was identified i.e. RM28130 associated with grain yield in TSD with the large $17.58 \%$ phenotypic variance. This result shows that RM28130 marker also link to QTL12.1 in this population. Besides the grain yield this marker also affect the other yield related and contributing traits like plant height (PHT), flag leaf length (FLL), flag leaf width (FLW) and Second leaf length (SLL) in both the conditions. Under TSD RM28130, and RM7195 was linked to harvest index (HI). The large phenotypic variance was observer for water stress (TSD) condition as compared to control condition (Irrigated) for all the physiological traits (Table 2 and 3).

A QTL (qDTY 12.1) on chromosome 12 was identified for GY under reproductive stage (RS) flanked by markers RM28099 and RM28199 showing a consistent effect in two seasons (Krishna Kumar et al., 2013). This study confirmed the effect of qDTY 12.1 under TSD conditions, which has not been seen before in a swarna sub 1/IR 84984-83-15-159B population.
IR 84984-83-15-159B is a drought tolerant upland-adapted cultivar and it possesses QTL 12.1 for grain yield under drought. On the other hand, swarna sub 1 is a highly droughtsusceptible high yielding popular rice variety adapted for large rice grown area allowing the effect of the $q D T Y 12.1$ allele

contributed by IR $84984-83-15-159$ B to be seen in even under drought severity. No one marker was identified with root pulling strength (RPS) in both the conditions.

Recently, candidate gene analysis has been carried out in this QTL region and several genes have been reported as putative candidate genes, including a GRAM-domain containing protein, an Amydohydrolase, a Nodulin MtN3, a No Apical Meristem, a Cellulose Synthase A (CesA10) and a cytochrome P450 associated with different processes such as root hair proliferation/elongation, pollen fertility, cell wall permeability and signal transduction (Kohli et al., 2010; Biswal et al., 2012). Swamy et al. (2011) carried out meta-QTL analysis and reported several candidate genes in the same region. $q D T Y$ 12.1 could be efficiently used in marker-assisted breeding for the improvement of both lowland and upland rice varieties for drought stress. Beside this on the basis of genotypic data and phenotypic observations under field conditions (TSD), out of 55 lines the line number $4,21,28,32,35,36$ and 37 were selected that are morphologically looks like recipient parent/ cultivar swarna sub1 but having the QTL $q D T Y 12.1$ (Figure 1) from donor IR $84984-83-15-159 \mathrm{~B}$.

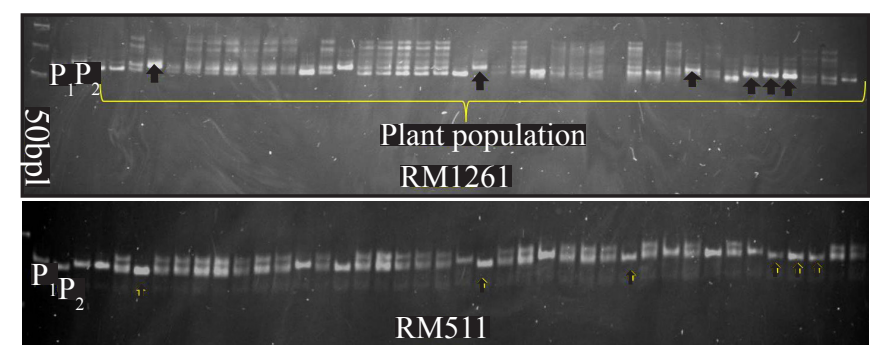

Figure1: Banding pattern of marker RM1261 and RM511 showing lines having $q D T Y 12.1$.

\section{Conclusion}

A major drought grain yield QTL on chromosome 12, $q D T Y$ 12.1, was identified showing a high and consistent effect across the population. The positive allele for $q D T Y 12.1$ was contributed by the tolerant parent IR 84984-83-15-159B. Based on a previous study conducted under the upland drought ecosystem in a Vandana/Way Rarem population and this study under the lowland drought ecosystem in a swarna sub1/ IR 84984-83-15-159B population, it could be concluded that qDTY 12.1 was important regions for improving grain yield under drought of susceptible varieties of both lowland and upland ecosystems following MAS. 


\section{Acknowledgement}

First author gratefully acknowledges the financial assistance in the form of fellowship by Department of Science and Technology, Govt. of India received during this work. Thanks are also due to the Head and Professor for providing field and laboratory facilities at the Department of plant molecular biology and biotechnology during the course of this investigation.

\section{References}

Allard, R.W.,1962. Principals of plant breeding. John Wiley \& Sons. New York, U.S.A, 608.

Babu, R.C., Nguyen, B.D., Chamarerk, V., Shanmugasundaram, P., Chezhian, P., Jeyaprakash, P., Ganesh, S.K., Palchamy, A., Sadasivam, S., Sarkarung, S., Wade, L.J., Nguyen, H.T., 2003. Genetic analysis of drought resistance in rice by molecular markers: association between secondary traits and field performance. Crop Science 43, 1457-1469.

Bate, B.C., Kundzewicz, Z.W., Wu, S., Palutikof, J.P., 2008. Climate Change and Water. Technical Paper of the Intergovernmental Panel on Climate Change IPCC Secretariat, Geneva 210 [http://www.ipcc.ch/pdf/ technical-papers/ climate-change-water-en.pdf].

Bernier, J., Kumar, A., Ramiah, V., Spaner, D., Atlin, G., 2007. A large effect of QTL for grain yield under reproductive stage drought stress in upland rice. Crop Science 47, 505-518.

Bernier, J., Kumar, A., Venuprasad, R., Spaner, D., Atlin, G.N., 2007. A large-effect QTL for GY under reproductivestage drought stress in upland rice. Crop Science 47, 507-516.

Biswal, A.K., Oane, R., Raorane, M., Narciso, J., Blesilda, A.E., Kumar, A., Kohli, A., 2012. Identification of candidate genes in the large effect QTL DTY12.1 for yield under stress, Presented at FCSSP Conference, held in Puerto Princesa City, Palawan, Philippines, April 16-21 2012.

Burton, G.W., DeVane, E.H., 1953. Estimating heritability in tall fescue (Festuca arundinacea) from replicated clonal material. Journal of Agronomy 45, 478-481.

Fukai, S., Cooper, M., 1995. Development of drought resistant cultivars using physio-morphological traits in rice. Field Crops Research 40, 67-86.

Gupta, S.K., Rathore, P., Singh, K., 2004. Genetic variability in mungbean [Vigna radiate (L.) Wilczek]. Leg. Res 25, 180-183.

Hozayn, M., El-Habbasha, S.F., Abd El-Lateef, E.M., Abd El- Monem, A.A., 2013. Genetic variability in 16 exotic mungbean genotypes for late sowing under Egyptian conditions. Journal of Applied Sciences Research 9, 643-651.

Johnson, H.W., Robinson, H.F., Comstock, R.E., 1955. Genetic and environmental heritability in soybean. Journal of Agronomy 47, 314-318.

Kohli, A., Narciso, J., Oane, R., Popluechai, S., Kumar, A., 2010. Identification of major candidate genes in a large effect QTL for rice yield under drought stress, Paper presented at International Rice Congress, Hanoi, Vietnam.

Kumar, A., Bernier, J., Verulkar, S., Lafitte, H.R., Atlin, G.N., 2008. Breeding for drought tolerance: direct selection for yield, response to selection and use of drought-tolerant donors in upland and lowland-adapted populations. Field Crops Research 107, 221-231.

Kumar, K., Prasad, K.D., Verma, A.K., 2003. Genetic variability, correlation and path co efficient analysis in green gram. Journal of Agriculture Research 15, 97-101.

Mishra, K.K., Vikram, P., Yadaw, R.B., Swamy, M., Dixit, S., Ma Teresa Sta Cruz, Maturan, P., Marker, S., Kumar, A., 2013. qDTY 12.1: a locus with a consistent effect on grain yield under drought in rice. BMC Genetics 14, 12 .

Panse, V.G., 1957. Genetics of quantitative characters in relation to plant breeding. Indian Journal of Genetics and Plant Breeding 17, 318-328.

Prashant, Vikram., B.P, Mallikarjuna Swamy, Shalabh Dixit1, Helal Uddin, Ahmed, Ma Teresa Sta Cruz, Alok Kumar Singh and Arvind Kumar., 2011. qDTY 1.1a major QTL for rice grain yield under reproductive-stage drought stress with a consistent effect in multiple elite genetic backgrounds. BMC Genetics 12, 89.

Singh, P., Narayanan, S.S.,1993. Biometrical Techniques in Plant Breeding. Kalyani Publishers, New Delhi (INDIA).

Standard evaluation system (SES), International Rice Research Instituted, Nov, 2002.

Swamy, B.P.M., Vikram, P., Dixit, S., Ahmed, H. U., Kumar, A., 2011. Meta-analysis of GY QTL identified during agricultural drought in grasses showed consensus. BMC Genomics 12, 319.

Vikram, P., Swamy, BPM., Dixit, S., Ahmed HU., Sta, Cruz M.T., Singh, A.K., Kumar, A., 2011. qDTY 1.1, major QTL for rice GY under reproductive-stage drought stress with a consistent effect in multiple elite genetic backgrounds. BMC Genetics 12, 89.

Wassmann, R., Jagadish, S.V.K., Sumfleth, K., Pathak, H., Howell, G., Ismail, A., Serraj, R., Redona, E., Singh, R.K., Heuer, S., 2009. Regional vulnerability of climate change impacts on Asian rice production and scope for adaptation. Advances in Agronomy 102, 91-133. 